\title{
Predictors of Clinical Outcomes after Intrastromal Corneal Ring Segments Implantation
}

\author{
Leonardo Torquetti, Guilherme Ferrara, Paulo Ferrara
}

\begin{abstract}
Purpose: To evaluate the influence of age and severity of keratoconus in the clinical outcomes of implantation of Ferrara intrastromal corneal ring segments (ICRS).
\end{abstract}

Methods: A total of 1,073 eyes of 810 patients, consecutively operated from January 2006 to July 2008, were evaluated. Two independent analysis were made according to the age of patients and keratoconus staging. Four groups were created according to the age of patients: < 20 years old, 20 to 30,30 to 40 and $>40$ years old. The patients were also evaluated according to the keratoconus stage (I to IV). The outcome analysis included uncorrected distance visual acuity (UDVA), corrected distance visual acuity (CDVA), keratometry (K), asphericity (Q), corneal volume (CV) and pachymetry. All patients were evaluated using the Pentacam.

Results: The postoperative increase in UDVA and CDVA was statistically significant in all groups $(p<0.05)$. The magnitude of improvement of CDVA was larger for patients between 21 and 30-year-old (CDVA $=20 / 40)$ and patients with keratoconus grade I (CDVA $=20 / 35)(p<0.05)$. There was a statistically significant increase in $\mathrm{CV}$ and pachymetry postoperatively in all groups. The keratometry (3.95D) and asphericity $(-0.77)$ reduction were larger in patients younger than 20-year-old and in patients with keratoconus grade IV $(p<0.05)$.

Conclusion: The best clinical outcomes are seen in patients between 20 and 30-year-old and initial cases of keratoconus (grade I). The more advanced the keratoconus, the larger magnitude of $\mathrm{K}$ and $\mathrm{Q}$ reduction after ICRS implantation.

Keywords: Keratoconus, Intrastromal corneal ring segments, Age, Severity of keratoconus.

How to cite this article: Torquetti L, Ferrara G, Ferrara P. Predictors of Clinical Outcomes after Intrastromal Corneal Ring Segments Implantation. Int J Keratoco Ectatic Corneal Dis 2012;1(1):26-30.

\section{Source of support: Nil}

Conflict of interest: None declared

\section{INTRODUCTION}

Intrastromal corneal ring segments (ICRS), which were initially designed to correct mild to moderate myopia, ${ }^{1,2}$ have been evaluated as a way to manage keratoconus in cases with a clear cornea and contact lens intolerance. The main advantages of ICRS are safety, ${ }^{3-5}$ reversibility and stability. ${ }^{6-8}$ In addition, the surgery preserves the integrity of the central cornea.

The ICRS implantation has been reported to provide effective outcomes for the treatment of patients with corneal thinning disorders like keratoconus, ${ }^{7,8}$ pellucid marginal degeneration $^{9,10}$ and post-LASIK ectasia. ${ }^{11,12}$ The goal of ring segment implantation is to improve visual acuity and to delay or avoid corneal grafts in patients with keratoconus.

The age of patients can, theoretically, interfere in visual and topographic results after ICRS implantation. A recently published paper showed that the stiffness of the human cornea increases by a factor of approximately two between the ages of 20 and 100 years. ${ }^{13}$ Moreover, the stage of keratoconus can also influence the outcomes after ICRS implantation, as in more severe cases it is expected suboptimal results, when compared to initial cases. ${ }^{14}$

The purpose of this study is to evaluate the influence of age and severity of keratoconus in the clinical outcomes of implantation of Ferrara ICRS.

\section{PATIENTS AND METHODS}

In the present study, 1073 eyes of 810 consecutive surgical patients from January 2006 to July 2008 were evaluated. In 972 eyes, one or two segments of an ICRS with $160^{\circ}$ of arc were implanted. In 101 eyes, one ICRS with $210^{\circ}$ of arc was implanted. We have done two independent analysis according to: (1) Age of patients and (2) keratoconus staging. The patients were divided into four groups according to its age: $<20$ years old, 21 to 30 years old, 31 to 40 years old and $>40$ years old (Table 1 ). Moreover, patients were divided into four groups regarding the stage of keratoconus, according to the mean keratometry (Km): Grade I (Km $<46 \mathrm{D})$, grade II $(46<\mathrm{Km}<52 \mathrm{D})$, III $(52<$ $\mathrm{Km}<60 \mathrm{D})$ or IV $(\mathrm{Km}>60 \mathrm{D})$.

Inclusion criteria were contact lens intolerance and/or evidence of ectasia progression as measured by worsening of uncorrected distance visual acuity (UDVA) and corrected distance visual acuity (CDVA), progressive intolerance to contact lens wear and progressive corneal steepening documented by topographical changes. Two or more lines of UDVA and/or CDVA worsening and at least 2 diopters (D)

Table 1: General data of patients

\begin{tabular}{lccc}
\hline Age (years) & Eyes $(n)$ & Age $(Y)$-(range) & Sex $(F / M)$ \\
\hline$<20$ & 98 & $17 \pm 2.25(10-19)$ & $68 / 30$ \\
$20-30$ & 546 & $23 \pm 3.93(20-29)$ & $224 / 302$ \\
$30-40$ & 292 & $33 \pm 2.96(30-39)$ & $107 / 195$ \\
$>40$ & 142 & $47 \pm 6.85(40-74)$ & $88 / 59$ \\
\hline
\end{tabular}

$\mathrm{p}$-values $=$ mean $\pm \mathrm{SD}$ 
of increase in mean keratometry $(\mathrm{K})$ as measured with a Pentacam (Oculus Optikgerate $\mathrm{GmbH}$ ), were required to define progression of the disease. Exclusion criteria included any of the following discovered during the preoperative examination: Advanced keratoconus with curvatures over 62D, significant apical opacity and scarring, hydrops, corneas with thickness below $300 \mu \mathrm{m}$ in the ring track as evaluated by Pentacam pachymetry and intense unresolved atopia, which is more appropriately treated before implantation.

\section{CLINICAL MEASUREMENTS}

A complete ophthalmologic examination was performed before surgery and included UDVA and CDVA assessment, biomicroscopy, fundoscopy, tonometry, corneal topography, pachymetric map and asphericity (Q) measurement using the Pentacam HR. All clinical examinations were performed in a standardized manner by an independent, experienced examiner (PF). At the last follow-up examination, manifest refraction, UDVA, CDVA, slit-lamp and topographic examinations were performed.

\section{SURGICAL TECHNIQUE}

All surgeries were performed by the same surgeon (PF) using the manual technique. The arc and thickness of the ICRS were selected according to a previously described nomogram that is based on the position of the keratoconus on the cornea, topographic astigmatism and the pachymetric map. ${ }^{4,5}$ The nomogram determines the ring thickness to be implanted. The surgery was performed under topical anesthesia after miosis was achieved with $2 \%$ pilocarpine. An eyelid speculum was used to expose the eye, and 2.5\% povidone iodine eyedrops were instilled onto the cornea and conjunctival cul-de-sac. The visual axis was marked by pressing a Sinskey hook on the central corneal epithelium while asking the patient to fixate on the corneal light reflex of the microscope light. Using a marker tinted with gentian violet, a $5.0 \mathrm{~mm}$ optical zone and incision site were aligned to the desired axis in which the incision would be made. This incision site was always the steepest topographic axis of the cornea given by the Pentacam.

A square diamond blade was set at $80 \%$ of corneal thickness as determined by the pachymetric map at the incision site. Using a 'stromal spreader', a pocket was formed in each side of the incision. Two $270^{\circ}$ semicircular dissecting spatulas, clockwise and counterclockwise, were consecutively inserted through the incision and gently pushed with some, quick, rotary 'back and forth' tunneling movements. Following channel creation, the ring segments were inserted using a modified McPherson forceps. The rings were properly positioned with the aid of the Sinskey hook.

The postoperative regimen consisted of moxifloxacin $0.5 \%$ (Vigamox ${ }^{\circledR}$, Alcon, Ft Worth, TX, USA) and dexamethasone $0.1 \%$ (Maxidex $^{\circledR}$, Alcon) eye drops four times daily for 2 weeks. The patients were instructed to avoid rubbing the eye and to frequently use preservativefree artificial tears (Oftane ${ }^{\circledR} 0.4 \%$, Alcon). The patients were examined postoperatively at 1 day, 1,3 and 6 months and 1 year after the surgery. After the first year, the patients were evaluated annually. The mean follow-up time was based on the time of the last visit.

\section{STATISTICAL ANALYSIS}

The GraphPad Instat software was used for descriptive statistics, including means \pm standard deviations and to test group differences for continuous variables. Student's t-test for paired data was used to compare preoperative and postoperative data. Statistical analysis was done using independent sample t-tests to compare variables between groups. p-values less than 0.05 were considered statistically significant.

\section{RESULTS}

The mean follow-up time of operated patients was $23.8 \pm$ 12.2 months. The majority of patients were between 21 and 30-year-old (Table 1).

The preoperative keratometry values were similar for all age groups. There was a statistically significant reduction of keratometry for all groups, and the amount of this reduction was larger for patients $<20$ years old (Table 2 ). The asphericity values were more negative for patients $<20$ years old, however, the postoperative $\mathrm{Q}$ values were similar between groups. The change in $\mathrm{Q}$ value was larger for patients $<20$ years old than for older patients $(p<0.05)$.

Table 2: Preoperative and postoperative $\mathrm{K}$ and $\mathrm{Q}$, according to the age

\begin{tabular}{lcccccccc}
\hline Age (years) & $\begin{array}{c}\text { Preoperative } \\
K m(D)\end{array}$ & $\begin{array}{c}\text { Postoperative } \\
K m(D)\end{array}$ & $p$-value & $\Delta K m(D)$ & $\begin{array}{c}\text { Preoperative } \\
Q(\mu m)\end{array}$ & $\begin{array}{c}\text { Postoperative } \\
Q(\mu m)\end{array}$ & $p$-value & $\Delta Q(\mu m)$ \\
\hline$<20$ & $49.75 \pm 4.83$ & $45.80 \pm 3.80$ & $<0.01$ & 3.95 & $-1.09 \pm 0.63$ & $-0.36 \pm 0.63$ & $<0.01$ & -0.73 \\
$21-30$ & $49.43 \pm 4.54$ & $45.86 \pm 3.82$ & $<0.01$ & 3.57 & $-0.90 \pm 0.45$ & $-0.38 \pm 0.51$ & $<0.01$ & -0.52 \\
$31-40$ & $49.51 \pm 4.13$ & $46.11 \pm 3.62$ & $<0.01$ & 3.40 & $-0.85 \pm 0.48$ & $-0.39 \pm 0.55$ & $<0.01$ & -0.46 \\
$>40$ & $49.54 \pm 4.60$ & $46.40 \pm 4.30$ & $<0.01$ & 3.14 & $-0.77 \pm 0.57$ & $-0.29 \pm 0.70$ & $<0.01$ & -0.48 \\
\hline
\end{tabular}

$\mathrm{p}$-values $=$ mean $\pm \mathrm{SD}$ 
There was a statistically significant increase in corneal volume and corneal thickness in all groups, postoperatively, however, there was no difference intergroup $(p>0.05)$ (Table 3). The mean UDVA and CDVA increased in all groups ( $<<0.01$, Table 4 ). The magnitude of improvement of CDVA was larger for patients between 21 and 30-year-old $(C D V A=20 / 40)$ and in patients with keratoconus grade I $(C D V A=20 / 35)(p>0.05)$. The changes in keratometry and as phericity were statistically significant in all keratoconus grades (Table 5).

\section{DISCUSSION}

Improvement in visual acuity and refraction after ICRS implantation is accomplished by shortening the path length of the portion of the collagen lamellae that are central to the segments. Redistribution of corneal curvature leads to a redistribution of corneal stress, interrupting the biomechanical cycle of the keratoconus progression and in some cases reversing the stress. ${ }^{15}$

The goal of ICRS implantation is to stabilize and reinforce the ectatic cornea. It takes approximately 6 months for ICRS implantation to show an effect on the cornea and improve the visual acuity because of the viscoelastic nature of the cornea. ${ }^{16}$

Alió et $\mathrm{al}^{17}$ have reported good outcomes in a similar group to our study, with a mean age of $29.5 \pm 7.05$ years and consisting of $75 \%$ males. Poorer outcomes and higher complication rates have been reported in older patient populations with a female predominance by Alió et $\mathrm{al}^{17}$ and Kanellopoulos et al. ${ }^{18}$ The preoperative predictors of a good outcome have been reported to be lower initial keratometric readings ( $\mathrm{K}<53 \mathrm{D}$ ), better preoperative CDVA, lower astigmatism and spherical myopia. ${ }^{17}$ Our study results confirm some of these data, as the best clinical outcomes were found in stage I keratoconus, in which the keratometry readings are low and the UDVA and CDVA are better.

We found a significant increase in corneal thickness in all groups. In theory, this can be explained by corneal collagen remodeling induced by the implantation of the ICRS. ${ }^{19,20}$ By acting as 'spacers', the ring segments could interfere with corneal collagen turnover, with consequent increases in the corneal pachymetry.

There was a significant decrease in asphericity values after implantation of the ICRS. Most studies agree that

Table 3: Preoperative and postoperative CV and TCT

\begin{tabular}{|c|c|c|c|c|c|c|c|c|}
\hline $\begin{array}{l}\text { Age } \\
\text { (years) }\end{array}$ & $\begin{array}{l}\text { Preoperative } \\
\text { CV }\left(\mathrm{mm}^{3}\right)\end{array}$ & $\begin{array}{l}\text { Postoperative } \\
\text { CV }\left(\mathrm{mm}^{3}\right)\end{array}$ & $p$-value & $\Delta C V\left(m^{3}\right)$ & $\begin{array}{c}\text { Preoperative } \\
\text { TCT }(\mu \mathrm{m})\end{array}$ & $\begin{array}{c}\text { Postoperative } \\
\text { TCT }(\mu \mathrm{m})\end{array}$ & $p$-value & $\triangle T C T(\mu m)$ \\
\hline$>20$ & $58.2 \pm 4.0$ & $59.0 \pm 4.3$ & $<0.01$ & 0.86 & $459.6 \pm 48.2$ & $470.8 \pm 50.2$ & $<0.01$ & 11.1 \\
\hline $21-30$ & $57.2 \pm 3.3$ & $58.3 \pm 3.3$ & $<0.01$ & 1.1 & $450.0 \pm 41.8$ & $465.8 \pm 49.8$ & $<0.01$ & 15.8 \\
\hline $31-40$ & $56.1 \pm 3.8$ & $57.5 \pm 3.8$ & $<0.01$ & 1.4 & $437.1 \pm 47.9$ & $458.8 \pm 50.0$ & $<0.01$ & 21.7 \\
\hline$>40$ & $56.9 \pm 4.2$ & $58.0 \pm 4.1$ & $<0.01$ & 1.1 & $440.0 \pm 48.5$ & $457.8 \pm 47.4$ & $<0.01$ & 17.8 \\
\hline
\end{tabular}

p-values $=$ mean \pm SD

Table 4: Preoperative and postoperative UDVA and CDVA, according to the age and severity of keratoconus

\begin{tabular}{|c|c|c|c|c|c|c|}
\hline Age (years) & $\begin{array}{l}\text { Preoperative } \\
\text { UDVA }\end{array}$ & $\begin{array}{l}\text { Postoperative } \\
\text { UDVA }\end{array}$ & $p$-value & $\begin{array}{l}\text { Preoperative } \\
\text { CDVA }\end{array}$ & $\begin{array}{l}\text { Postoperative } \\
\text { CDVA }\end{array}$ & $p$-value \\
\hline$>20$ & $20 / 240$ & $20 / 100$ & $<0.01$ & $20 / 110$ & $20 / 55$ & $<0.01$ \\
\hline $31-40$ & $20 / 170$ & $20 / 70$ & $<0.01$ & $20 / 110$ & $20 / 47$ & $<0.01$ \\
\hline$>40$ & $20 / 270$ & $20 / 70$ & $<0.01$ & 20/105 & $20 / 50$ & $<0.01$ \\
\hline \multicolumn{7}{|l|}{ Grades } \\
\hline II & $20 / 220$ & $20 / 80$ & $<0.01$ & $20 / 94$ & $20 / 40$ & $<0.01$ \\
\hline III & $20 / 250$ & $20 / 100$ & $<0.01$ & $20 / 400$ & $20 / 55$ & $<0.01$ \\
\hline IV & $20 / 800$ & $20 / 200$ & $<0.01$ & $20 / 400$ & $20 / 90$ & $<0.01$ \\
\hline
\end{tabular}

p-values $=$ Mean \pm SD

Table 5: Preoperative and postoperative $\mathrm{K}$ and $\mathrm{Q}$, according to the severity of keratoconus

\begin{tabular}{|c|c|c|c|c|c|c|c|c|}
\hline $\begin{array}{l}\text { Grade } \\
\text { (I-IV) }\end{array}$ & $\begin{array}{l}\text { Preoperative } \\
\mathrm{Km} \text { (D) }\end{array}$ & $\begin{array}{l}\text { Postoperative } \\
\mathrm{Km} \text { (D) }\end{array}$ & $p$-value & $\Delta K m(D)$ & $\begin{array}{l}\text { Preoperative } \\
Q(\mu \mathrm{m})\end{array}$ & $\begin{array}{c}\text { Postoperative } \\
Q(\mu \mathrm{m})\end{array}$ & $p$-value & $\Delta Q(\mu m)$ \\
\hline I & $45.50 \pm 2.35$ & $43.0 \pm 2.61$ & $<0.01$ & 2.5 & $-0.52 \pm 0.27$ & $-0.08 \pm 0.43$ & $<0.01$ & -0.44 \\
\hline II & $48.50 \pm 2.87$ & $45.3 \pm 2.71$ & $<0.01$ & 3.2 & $-0.84 \pm 0.32$ & $-0.33 \pm 0.49$ & $<0.01$ & -0.51 \\
\hline III & $52 \pm 4.11$ & $47.7 \pm 3.69$ & $<0.01$ & 4.3 & $-0.85 \pm 0.37$ & $-0.55 \pm 0.34$ & $<0.01$ & -0.58 \\
\hline IV & $61.5 \pm 4.83$ & $54.10 \pm 479$ & $<0.01$ & 7.4 & $-1.96 \pm 0.55$ & $-1.3 \pm 0.60$ & $<0.01$ & -0.66 \\
\hline
\end{tabular}

$\mathrm{p}$-values $=$ mean $\pm \mathrm{SD}$ 
human cornea asphericity values range from -0.01 to $-0.80 .{ }^{21-23}$ Currently, the most commonly accepted value in a young adult population is approximately -0.23 . $^{24}$ The asphericity can be considered as one of the markers of visual quality. Thus, returning it closer to 'normal' or at least reducing the excess prolateness usually found in keratoconus, could be a predictor of improved visual quality.

Most patients of this study were between 21 and 40 years old. There was no statistically significant $(\mathrm{p}>0.05)$ change in $\Delta \mathrm{Km}, \Delta \mathrm{CV}$ and $\Delta \mathrm{TCT}$ when compared among the different age groups. The $\Delta \mathrm{Q}$ was larger $(\mathrm{p}<0.05)$ for patients younger than 20 years old. As the corneal asphericity has been considered as a more reliable parameter for corneal remodeling, ${ }^{25}$ the larger changes in this parameter in younger patients can be a result of a less stiff cornea, more prone to changes induced by ICRS.

There was improvement of UDVA and CDVA, from preoperative to postoperative, in all age groups. There was no statistically significant difference in UDVA and CDVA among the groups $(p>0.05)$. However, the CDVA was better for patients between 21 and 30 years old. Concerning the stage of the keratoconus, the more initial the stage the better the UDVA and CDVA $(\mathrm{p}<0.05)$.

Miranda et $\mathrm{al}^{14}$ obtained a significant reduction in the postoperative central corneal curvature, the CDVA and UDVA improved in 87.1 and $80.6 \%$ of the eyes respectively. Siganos et $\mathrm{al}^{3}$ showed an increase of the UDVA from 20/ 285 preoperatively to 20/100 and 20/60 after 1 and 6 months respectively. The BDVA improved from 20/55 preoperatively to 20/40 and 20/33 after 1 and 6 months respectively. We found similar results in our study, which confirms the reproducibility of the technique.

The more advanced the keratoconus the larger the amount of $\mathrm{K}$ reduction and Q increase. This seems to be related to the biomechanics of the cornea, i.e. the steeper the cornea, the larger the response to a given implanted ICRS.

The variation of corneal biomechanics with age, may play a role in different clinical outcomes after ICRS implantation, when an age-matched analysis is performed. Elsheikh et al, ${ }^{26}$ conducted an experimental study to determine the stress-strain behavior of human corneal tissue and how the behavior varies with age. They found a strong statistical association between stiffness and age $(\mathrm{p}<0.05)$. A recent study showed that corneal biomechanical parameters are significantly decreased by aging without significant changes in central corneal thickness, suggesting that age-related structural changes resulting from collagen cross-linking may lead to a reduction of corneal biomechanical variables independent of central corneal thickness. ${ }^{27}$

\section{CONCLUSION}

ICRS implantation was effective in reducing the keratometry, corneal asphericity, increasing corneal volume and thickness and improving UDVA and CDVA. Patients with age between 21 and 30 years old and with grade I keratoconus can benefit more from ICRS implantation. The role of age, gender, cone position and evolutive grade as predictors of better outcomes, needs to be better evaluated. Further studies and long-term follow-up reports are required to determine other predictors of a good visual outcome and to develop criteria for patient selection.

\section{REFERENCES}

1. Nose W, Neves RA, Burris TE, et al. Intrastromal corneal ring: 12-month sighted myopic eyes. J Refract Surg 1996;12:20-28.

2. Schanzlin DJ, Asbell PA, Burris TE, Durrie DS. The intrastromal ring segments; phase II results for the correction of myopia. Ophthalmology 1997;104:1067-78.

3. Siganos D, Ferrara P, Chatzinikolas K, et al. Ferrara intrastromal corneal rings for the correction of keratoconus. J Cataract Refract Surg 2002;28:1947-51.

4. Kwitko S, Severo N. Ferrara intracorneal ring segments for keratoconus. J Cataract Refract Surg 2004;30:812-20.

5. Ferrara P, Torquetti L. Clinical outcomes after implantation of a new intrastromal ring with a 210 degree of arch. J Cataract Refract Surg 2009;35:1604-08.

6. Alió JL, Shabayek MH, Artola A. Intracorneal ring segments for keratoconus corrections: Long-term follow-up. J Cataract Refract Surg 2006;32:978-85.

7. Colin J, Cochener B, Savary G, Malet F. Correcting keratoconus with intracorneal rings. J Cataract Refract Surg 2000;26: 1117-22.

8. Torquetti L, Ferrara P. Long-term follow-up of intrastromal corneal ring segments in keratoconus. J Cataract Refract Surg 2009;35:1768-73.

9. Mularoni A, Torreggiani A, di Biase A, Laffi GL, Tassinari G. Conservative treatment of early and moderate pellucid marginal degeneration: A new refractive approach with intracorneal rings. Ophthalmology 2005;112(4):660-66.

10. Kubaloglu A, Sari ES, Cinar Y, Koytak A, Kurnaz E, Pinero D, et al. A single 210 degree arc length intrastromal corneal ring implantation for the management of pellucid marginal corneal degeneration. Am J Ophthalmol 2010;150:185-92.

11. Torquetti L, Ferrara P. Intrastromal corneal ring segment implantation for ectasia after refractive surgery. J Cataract Refract Surg 2010;36:986-90.

12. Siganos CS, Kymionis GD, Astyrakakis N, et al. Management of corneal ectasia after laser in situ keratomileusis with INTACS. J Refract Surg 2002;18:43-46.

13. Knox Cartwright NE, Tyrer JR, Marshall J. Age-related differences in the elasticity of the human cornea. Invest Ophthalmol Vis Sci 16 Sep 2010.

14. Miranda D, Sartori M, Francesconi C, Allemann N, Ferrara P, Campos M. Ferrara intrastromal corneal ring segments for severe keratoconus. J Refract Surg Nov-Dec 2003;19(6):645-53.

15. Ertan A, Kamburoglu G. Intacs implantation using a femtosecond laser for management of keratoconus: Comparison of 306 cases in different stages. J Cataract Refract Surg 2008;34:1521-26. 
16. Dauwe C, Touboul D, Roberts CJ, Mahmoud AM, Kérautret J, Fournier P, et al. Biomechanical and morphological corneal response to placement of intrastromal corneal ring segments for keratoconus. J Cataract Refract Surg Oct 2009;35(10):1761-67.

17. Alió JL, Shabayek MH, Belda JI, et al. Analysis of results related to good and bad outcomes of Intacs implantation for keratoconus correction. J Cataract Refract Surg 2006;32:756-61.

18. Kanellopoulos AJ, Pe LH, Perry HD, et al. Modified intracorneal ring segment implantations (INTACS) for the management of moderate to advanced keratoconus: Efficacy and complications. Cornea 2006;25:29-33.

19. Flynn BP, Bhole AP, Saeidi N, et al. Mechanical strain stabilizes reconstituted collagen fibrils against enzymatic degradation by mammalian collagenase matrix metalloproteinase 8 (MMP-8). PLoS One 2010 Aug 23;5(8):12337.

20. Mackiewicz Z, Määttä M, Stenman M, et al. Collagenolytic proteinases in keratoconus. Cornea Jun 2006;25(5):603-10.

21. Davis WR, Raasch TW, Mitchell GL, et al. Corneal asphericity and apical curvature in children: A cross-sectional and longitudinal evaluation. Invest Ophthalmol Vis Sci 2005; 46:1899-1906.

22. Holmes-Higgin DK, Baker PC, Burris TE, Silvestrini TA. Characterization of the aspheric corneal surface with intrastromal corneal ring segments. J Refract Surg 1999;15:520-28.

23. Eghbali F, Yeung KK, Maloney RK. Topographic determination of corneal asphericity and its lack of effect on the refractive outcome of radial keratotomy. Am J Ophthalmol 1995;275-80.
24. Yebra-Pimentel E, González-Méijome JM, Cerviño A, et al. Asfericidad corneal en una poblácion de adultos jóvenes. Implicaciones clínicas. Arch Soc Esp Oftalmol 2004;79: 385-92.

25. Torquetti L, Ferrara P. Corneal asphericity changes after implantation of intrastromal corneal ring segments in keratoconus. J Emmetropia 2010;1:178-81.

26. Elsheikh A, Geraghty B, Rama P, Campanelli M, Meek KM. Characterization of age-related variation in corneal biomechanical properties. J R Soc Interface Oct 6 2010;7(51):1475-85.

27. Kamiya K, Shimizu K, Ohmoto F. Effect of aging on corneal biomechanical parameters using the ocular response analyzer. J Refract Surg Oct 2009;25(10):888-93.

\section{ABOUT THE AUTHORS}

\section{Leonardo Torquetti (Corresponding Author)}

Department of Cornea, Paulo Ferrara Eye Clinic, Minas Gerais, Brazil e-mail: leonardotorqueti@yahoo.com.br

\section{Guilherme Ferrara}

Department of Cornea, Paulo Ferrara Eye Clinic, Minas Gerais, Brazil

\section{Paulo Ferrara}

Department of Cornea, Paulo Ferrara Eye Clinic, Minas Gerais, Brazil 